\title{
Anti-cheating type job submission system design and implementation
}

\author{
Xiaoying Zhan \\ Department of Electrical Engineering, Guangxi Technological College of Machinery and Electricity, \\ Nanning, 530007, China
}

Keywords: anti-cheating; electronic submission system; student work.

\begin{abstract}
On the computer classroom, most students using FTP or shared submit electronic work, but this method can easily lead to plagiarism. In this paper, to solve this problem in higher vocational colleges student characteristics, design and implementation of the job submission system, a great job of avoiding plagiarism student behavior, but also to facilitate the management of electronic operation of teachers, improving teachers' electronic operations management efficiency.
\end{abstract}

\section{Introduction}

Operating income is an important part of the daily work of teaching, education evaluation system is an important part. In computer class teaching vocational colleges, the job is in the form of electronic documents that appear in the network environment, there are many ways to collect and distribute the job, and the more common are the following: First, the shared folder. Second, the FTP mode. Third, the use of electronic classrooms submitted. But these three forms to submit a job, there are many drawbacks, it is difficult to put an end to acts of student plagiarism job.

And the quality of college students in vocational schools generally low, poor student learning initiative, Chaozuo Ye quite serious. As a commitment to teaching computer courses and management, and how to get the students to submit the job quick and easy, but also to put an end to the phenomenon Chaozuo Ye, in order to fully mobilize the enthusiasm of students, promote classroom teaching. Aiming at this problem, the design and development of this lack of LAN-based anti-plagiarism transceiver system operating room, in order to improve the way traditional electronic job submission, in addition to improving teachers' electronic operations management efficiency.

\section{First, the system design ideas}

Vocational colleges for courses in computer class room in the status quo, taking into account the student's work may take a few lessons to complete, so students should be able to submit electronic work and facilitate retrieval and copying operations to prevent the occurrence of the phenomenon; teachers can easily collect the student's mainly electronic marking jobs. Therefore, the architecture of the system design using C / S (Client / Server that the client and server) structure, this structure is built for the entire job submission system more quickly, easily and for electronic submission and daily management operations like building sites and FTP so complex, students and teachers function better machine to be controlled, thus preventing student plagiarism job fair for students to build a learning environment, but also improve the teachers' classroom management efficiency.

\section{Second, the system function description}

System to achieve structured and object-oriented technology, the entire system is divided into student information maintenance module, the student job submission module, teacher job management module, three function relatively independent sub-module, making the system level clear, well-structured, easy to maintain and use. Each module functions as follows:

\section{Student Information Maintenance Module}

The main function of this module is for students and teachers as well as the corresponding userdefined function to initialize the permissions so that users can carry out different identities in 
different types of operations, to streamline operations and security information.

\section{Student job submission module}

The main function of this module is to achieve student's electronic documents will be submitted to the server job (or teacher machine), and the student-related information (such as student number, name, etc.) to be submitted to complete the submission of electronic job. And can view or retrieve all electronic work previously submitted at any time.

\section{Teacher job management module}

Teacher module to complete the job directory to create the directory permissions, upload and submit job information has been marking off the job for students query. Read and write permissions set includes the job and upload permissions settings, job information, including teacher name, job subjects, upload time, the job turned deadline and batch jobs and so on. For students in the class work, teachers can by date and day of class sections queries student assignments handed situation and facilitate easy export marking inspection operations.

\section{Third, the system core module and key technologies}

The system is developed using Visual Studio.Net 2008, Visual Studio.NET is the next most powerful NET platform development tools, including the provision of basic functional design, coding, debugging and compiling a database connection and operation of the server components based on open architecture development platform, enterprise development tools and application republishing tools, and performance evaluation report and other advanced features, VB.NET based entirely on modules and components, has better scalability and customization, data processing also provides developers with the flexibility to better sex, effectively shortening the development cycle of the application.

\section{System Settings module}

This module includes a setting to share and share permissions directory, because the system uses a teacher / server approach to achieve full sharing of job submission, if we adopt a simple shared file name plus password to access, in a short time students are not easy to break, but for a long time will let students know, causing the contents of the shared folder student arbitrarily changed or deleted.

The method adopted in this system is to use a shared name to a name server for the seed to generate an encrypted 79 full keyboard symbols, and finally add the shared hidden character $\$$, so that the students even know the shared symbols, there is no way remember and access the shared folder, thus increasing the security of the code as shown below.

Private Function GetshareName (Tname as String) As String

Dim i As Integer, j As Integer,t As String,c As Integer, rndNum As Integer

For $\mathrm{j}=8$ To 1 Step -1

For $\mathrm{i}=1$ to Len (Tname)

$\mathrm{c}=$ Asc(Mid(LCase(Tname) $\mathrm{i}, 1)$ )

If $\mathrm{c}>=97$ And $\mathrm{c}<=122$ Then

$\mathrm{c}=\mathrm{c}+\mathrm{j}$

If $\mathrm{c}>122$ Then $\mathrm{c}=\mathrm{c}-26$

ElseIf $\mathrm{c}>=48$ And $\mathrm{c}<=57$ Then

$\mathrm{c}=\mathrm{c}+\mathrm{j}$

If $\mathrm{c}>57$ Then $\mathrm{c}=\mathrm{c}-10$

End If

$\mathrm{t}=\mathrm{t} \& \operatorname{Chr}(\mathrm{c})$

Next i

Next $\mathrm{j}$

For $\mathrm{i}=1$ To 3

$\mathrm{t}=\mathrm{t} \& \mathrm{t}$

Next

If Len $(t)>80$ Then $t=$ Left $(t, 79)$

GetshareName $=\mathrm{t}$ 


\section{End Function}

Student job submission / retrieval module. Students complete the job submission module mainly function to upload electronic documents, while the student-related information (such as student number, name, etc.) to be submitted to complete the submission of electronic job and be able to view or retrieve all electronic work previously submitted at any time. In this module, the most critical technology is the student can submit or retrieve their own jobs, the system does not take the form of an account and password to access the teacher machine, but taking into account all the room in the student machine name is not the same while each semester students generally are fixed seat number, based on this consideration, the practices of this system are: the student when submitting a job, students enter the school number a, B plus the name of the student machine name $\mathrm{C}$ three integrated together (eg A_B_C) as the file name to write to the shared directory of teachers machine, so as not to conflict with other work submitted by students. When students submit their own view jobs, but also to connect the machine according to the machine name and enter the name of the student number together, before they can get their jobs handed to achieve avoid plagiarism among students in each occurrence.

Teachers job management module. This module is relatively simplified in this system, because the system when students submit the job, the system has been based on the current time, where students combine user class schedule, students handed the job to write every day in different directories, such as teacher at June 1, 2013 8: 00-8: 45 class, students will be generated on the master computer a name when submitting a job as "20130601 section 1" directories, all students jobs in this directory, if to the first four lessons will "20130601 section 4," the directory appears. Just open the shared directory so the teacher job submission, you can glance.

Convenient school students find their homework, so as to facilitate the student's electronic browsing or copy jobs.

To prevent student plagiarism module. In traditional computer training teaching, students in the course of practicing teachers in the room difficult to monitor and manage electronic work between students is easy to copy each other, copying each other, which can seriously affect the enthusiasm of the students do their homework and teaching effectiveness. To prevent jobs from each other plagiarism among students, the majority of the operating system by way of user names and passwords to control access to students, but in the class room, students are together, between the students can easily exchange account and password.

The system analysis method to each student in the room roughly copying job has the following three ways: 1) together with the teacher machine to access a shared folder; 2) the student computers that share access; 3) U disk copy; therefore, if we can put these three channels to students blocked, bound to the effective control of student plagiarism phenomenon jobs, the present system is taken as follows:

Step 1: Log from the perspective of students. Students on the machine must be condemnation, student number and machine number must be the same; and this system is also available to students in the account number and the machine is bound, if the student sit chaos seat, the system will prohibit students from landing.

Step 2: From the perspective of the teachers shared machine. Sharing the file name with the symbol \$, is set to a hidden share, so that students can easily find a shared folder, if homework program uses a long, shared file folders or teacher machine is likely to be aware of the students, will lead students to copy someone else's job or prank delete other students work, the system solution is the shared directory using an encrypted manner, the specific method is to use a shared name to a name server for the seed to generate an encrypted 79 full keyboard symbols, and hidden in the final with a shared symbol \$, so that the students even know the shared symbols, there is no way to remember and access the shared folder, which enhances security.

Step 3: From the perspective of the students shared machine. Prohibit students shared machine, the system by stopping the Server service for all students and teachers end Browser service in order to achieve the purpose of prohibiting the students shared their own machine.

Which prohibits student machines share part of the code module as follows: 
net use \\PCXXX \ipc \$ / user: administrator "'"

sc $\backslash$ PCXXX stop browser

sc $\backslash$ PCXXX stop lanmanserver

Also disable the student machine $\mathrm{U}$ disk port.

\section{Conclusion}

This article questions the current school teachers receive electronic work presents the design of an anti-plagiarism job transceiver system implementations, the system realizes the teachers work with the students arranged job submission and review function, but also to facilitate the management of electronic teacher jobs. Through teaching practice, the initial use of the system to verify that students have a certain role in promoting the initiative, to some extent, improve the teaching effect, reduce the workload of teachers in class. For classroom teachers using electronic job submission systems provide examples and references.

\section{References}

[1] Ma and China, Wu Ruijun. Network Society and School Education [M]. Shanghai: Shanghai Education Press, 2002: 217-220.

[2] Wangzhuo Wei, Yin Baolin. A web-based program online evaluation system. Beijing University of Aeronautics [J], 2004, 6 (30): 502-505.

[3] Lianghe Jun jobs online support intelligent marking system design and implementation [D] Shanghai: Fudan University, 2008.

[4] Chen, Nie steel, Liu's first operating system for the AOL Web Assign Research and Enlightenment [J] Modern Distance Education, 2005 (3): 79-81.

[5] hand-Wen Sun, Peng Deng, Zhu Zhiting. Build technology-based edutainment experience learning environment [J]. China Educational Technology, 2005, (7).

[6] Kekang. Instructional System Design [M]. Beijing: Beijing Normal University Press, 2006 (103). 